Recognizing that the production metaphor best fits the stages of normal culture production, Heirich shows how scientific, artistic, and religious modes of inquiry build upon societal roots to produce cultural breakthroughs of revolutionary character.

\title{
Cultural Breakthroughs
}

\author{
MAX HEIRICH \\ University of Michigan
}

Thomas Kuhn, the historian of science, distinguishes between what he calls "normal science" and "scientific revolutions." The first term refers to everyday science, which proceeds within commonly accepted paradigms or models that suggest what the universe is like, what questions are relevant to ask, and how one should gather evidence relating to these questions. In a revolution, Kuhn (1970) argues, the paradigm. itself is changed so that quite different questions emerge, along with new procedures for answering them. Kuhn's distinction can be extended to cultural life more generally, to distinguish between those products that extend the understandings of their cultural world and those that fundamentally change the character of what appears later.

This paper focuses attention on changes of cultural perspective beyond the world of science. It will discuss the role a religious mode of inquiry plays in creating such "breakthrough" culture and will suggest social conditions conducive to the periodic intrusion of the religious mode into various areas of cultural life. The paper will contrast modes of inquiry with

Author's Note: I wish to thank Richard Peterson and Barbara Walters for their thorough and perceptive responses to an earlier version of this presentation. They will recognize a number of places where their arguments have affected the contents of this paper. 
market modes for cultural production, noting not only the tension found between these approaches to the creation of culture, but also the ways they sometimes interact to produce a major shift in cultural understanding.

Although the culture worlds of art, science, and religion differ in the products they generate, certain modes of inquiry are found in all three. For convenience, I shall call these modes of inquiry artistic, scientific, and religious; each mode is named for the kind of product it most encourages. What I call the artistic mode of inquiry is found not only in the world of art but also in science and religion. Scientific and religious modes of inquiry also are found in all three culture worlds. But each mode of inquiry focuses attention on different things. It is these different foci for attention that most distinguish the products of each culture world.

\section{MODES OF INQUIRY}

The artistic mode generates experiences that expand areas in which emotional reality can be shared rather than experienced in isolation. The artistic mode transforms human understanding by shifting our awareness of reality. In the field of art, the best products are approached as unique, one-of-a-kind experiences. This is partly an illusion, for artistic works of a particular time share understandings of reality that distinguish them from the products of another time period. Nonetheless, the essence of the artistic mode is the generation of experiences that touch their public deeply, that are experienced as unique, and that enlarge the range of what can be encountered collectively.

In contrast, the scientific mode of activity aims at simplifying the experience of reality by discovering principles of relationship that organize the complexity we see all around us. Careful attention to logical connections, to rules of verification and rejection, to the creation of emotional distance from the conclusions being considered, but not from the principles of inquiry being used, characterize the scientific mode. The task for the scientist is not the discovery of new areas of experience, 
but the organization of experience in terms of more abstract symbolic constructions.

The religious mode of cultural activity aims at discovering the Ground of Being from which other experiences of reality arise. It identifies the characteristics most important for coming to terms with that experienced Reality and for transforming the self, so that one can relate to those principles that organize "real" (as contrasted with illusory) Reality. This mode thus lies between the other two, partaking of elements of each of the others, but providing a focus that gives their activity quite different impact than they would have alone.

The religious mode does not necessarily require a conception of God or deities. Many of the more interesting religious responses today ignore such theological understandings, even as did such organized religions as Taoism or classic Buddhism. Indeed, both Paul Tillich and Peter Berger consider "non-sacred religion" to be the dominant form of religious understanding in the twentieth century (Tillich, 1959, 1969; Berger, 1969).

For most cultural production, the religious mode is not dominant. What might be called "normal culture" usually takes the commonly understood parameters for experiencing reality for granted, so that the Ground of Being in which events occur is not considered problematic. When the kind of breakthroughs in intellectual understanding occur that later get described as conceptual revolutions, however, the religious mode becomes far more central. Typically, they begin with a widening of experience (the artistic mode) that cannot be dealt with in terms of the normal framework for understanding reality. As the old frame dissolves, a new Ground of Being is asserted, whose dimensions become the parameters for organizing new experience. Within that new frame of reference, the simplifying sense of order that the scientific mode represents can then emerge.

\section{THE MARKET MODE OF PRODUCTION}

All three modes of inquiry that I have described assume that cultural products are valued in and of themselves, for the Truth 
they contain. In fact, however, cultural products often are produced for their exchange value as commodities. When the arrangements for funding cultural activity resemble those found in an economic market, "normal culture" subtly changes its character.

The dilemma of our time has been the degree to which the market mode has come to dominate all areas of cultural work. Most culture worlds (e.g., art, science, religion) develop a series of products that reflect the demands of their markets. Often this means that artistic, religious, or scientific conventions of style are used, independent of more fundamental modes of inquiry.

The vitality of cultural products does not depend upon their relation to "high" culture nor on the finesse with which they use the conventions of that culture world. (Consider, for example, the impact of Grandma Moses' painting.) Rather, vitality grows out of the seriousness with which the mode of inquiry is engaged.

\section{FADS AND BREAKTHROUGHS}

All culture worlds seem susceptible to the emergence of intellectual fads-temporary bursts of excitement that seem to reorient the focus of activity, only to grow stale and be replaced by new enthusiasms. The difference between a fad and an intellectual breakthrough, I suspect, lies deeper than the question of whether or not culture producers remain committed to its perspective over time. Fads generate initial excitement by using a particular mode of inquiry in a fresh way. Usually, however, they do not reexamine the assumptions of "normal culture," but rather shift attention within the already accepted framework. Consequently, their repetition over time eventually loses its impact. In contrast, a cultural breakthrough changes some aspect of the framework that is used to experience reality and understand it. Extensions of that outlook, as a consequence, continue to generate excitement for long periods of time and can eventually redefine "normal culture" as the perspective becomes widely shared. 
If I am correct in this basis for distinguishing between fads and breakthroughs, it follows that contemporaries should find it hard to distinguish between the two. Sometimes what appears to be a simple shift of emphasis actually changes the Ground of Being used to approach reality. Again, a dramatic shift of attention actually may leave the orienting framework undisturbed.

\section{THE EFFECTS OF DIFFERENT KINDS OF MARKETS}

I am convinced that the nature of the markets for cultural products affects the ease with which potential "breakthrough" products can emerge. Moreover, markets affect the kind of following such a product is likely to have once it has appeared. As examples, let us compare consumer goods markets, those of organized religion, and those of academia which is the home of most theological production as well as the home of most innovative science.

As I see it, the most important difference in markets serviced by academia, by organized religion, and by consumer goods industries relates to how funds are acquired for the various enterprises. In America, organized religion is similar to consumer industries in depending for resources upon contributions raised from individual "consumers." This stems from a competitive, denominational form of religious organization, from constitutional prohibitions on state subsidy of religion, and from the geographical mobility of the population which makes it easy for many adherents to switch allegiances or to drop away completely.

This structural similarity in market conditions leads to a number of activities in the two spheres which are directly parallel. I have pointed elsewhere (Heirich, 1974) to similarities in product differentiation by demographic market, in range of sales techniques used, in oligopolistic organization of the religious market as well as of most consumers markets, to a tendency toward mergers, toward similar use of "trade associa- 
tions," and toward similar criteria for the evaluation and promotion of personnel, based on management skills and on ability to increase income and membership. Just as in the case of consumer goods industries, the interplay of these factors makes for a succession of fads, not only in theology but also in the locus of sacred excitement for a larger public. Just as in the popular music industry, the length of the time that a sacred fad cycle remains dominant is about a decade (Heirich, 1974; Peterson, 1975).

Those parts of academia that are primarily teaching colleges and that depend upon individual tuition and fees (or upon legislative subsidy for teaching) reflect many of the characteristics just described. However, the more prestigious academic institutions (where the bulk of culturally innovative work that is shared beyond the immediate campus occurs) are dependent upon a different kind of market. They do not depend primarily on tuition or fees raised directly from individual consumers but on money from gifts, contracts, and grants.

Within prestigious universities, rewards are distributed on the basis of a star system, with "cultural innovators" eligible for star status, based upon a "publish or perish" tradition and review of performance by peers. Thus, individual access to rewards depends upon the opinion of colleagues both within and without one's own university. Institutional access to funds comes from a relatively small number of sources; the bulk of funds goes to units that are proven cultural innovators (i.e., to those who generate symbolic products that cause others to shift their way of thinking about the world and responding to it). Many of the funding sources are staffed by personnel who have themselves been academics; this is especially true of government grant agencies and private foundations. Thus, where religious innovators produce for a general public, academicians tend to produce for a relatively small set of peers, who control access to funds needed to carry on their activity.

The "publish or perish" tradition tends to generate high productivity; the star system encourages frequent new product designs within that production; and peer review, while it saves 
creative innovators from dependence upon the market as a whole, encourages the creation of products that are forwardlooking, but not too far out of step with those that others are producing.

Not surprisingly, given all this, intellectual fads are as pervasive a feature of academic life as they are of organized religion. There tends to be a regular succession of "hot topics" in various fields and stylish new theoretical perspectives. What occur for the most part, are faddish shifts of emphasis that leave the dominant frameworks very much intact. Peer review, after all, encourages conceptualizations that are innovative but not too extreme. But the market for new intellectual products will promote conceptual revolutions, just as it will promote more conservative shifts of fad.

\section{GENERATING CONCEPTUAL REVOLUTIONS}

Kuhn has relatively little to say about how conceptual revolutions are generated, other than to suggest that "normal science" gradually accumulates anomalies-findings that do not fit within the established paradigm. When enough of these accumulate, he suggests, people begin asking new questions that allow these findings to be taken into account. He does not try to explain the circumstances which allow anomalies to be taken seriously rather than dismissed-as, he contends, is the standard response within normal science. Nor does he identify the characteristics that make a new perspective revolutionary in its implications rather than merely different.

It seems to me that conceptual revolutions differ from intellectual fads in the following ways. First, they usually involve an experiential base that dissolves the parameters that have shaped previous ways of understanding events and meanings. Second, conceptual revolutions reorder the way parameters combine. Often only a single new ingredient is added, but it changes the values that each of the other concepts have, and consequently changes the organizing pattern for relationships that result when they interact. 
Thus, the difference between intellectual fads and conceptual revolutions lies deeper than the simple question of how long enthusiasm for a new perspective lasts. A more fundamental distinction concerns the extent to which the new orientation taps what I have called the religious mode of symbolization. To the extent that the Ground of Reality is seen afresh, a conceptual revolution occurs.

I believe that the religious mode of inquiry is most likely to result in what we think of as a conceptual revolution when two circumstances are present. First, it arises in response to disorienting experiences that are widely shared by some relevant public. Second, it occurs in a context that provides a network of support for alternative perspectives.

What kinds of experiences allow a new sense of ultimate framework to emerge? The inevitability of organizing assumptions begins to dissolve for many observers when either of two situations occurs. First, if a large number of people begin to have experiences on a fairly regular basis that contradict what should be possible, it is only a matter of time until someone is likely to suggest a different set of organizing parameters for understanding these events. Second, fundamental reexamination of organizing perspectives also can be expected during time periods when quite undesirable outcomes seem to be imminent and unavoidable if reality operates in the ways one has previously assumed. These two situations are secularized statements of the classic view that religious response most often results either from mystical encounter (that shatters one's sense of the past and opens new possibilities for Reality) or from the experience of Judgment (when one is brought face to face with the consequences of living out of tune with an Ultimate sense of order).

\section{RECENT DEVELOPMENTS}

The Vietnam war, interestingly enough, seems to have created the circumstances in American intellectual circles, for both of these responses to emerge. In the mid-1960s the 
escalation of the war in Vietnam produced a strong protest movement in the United States, particularly among the generation tapped for direct participation in that venture. That protest centered on university campuses and produced some unexpected spin-offs.

First, the antiwar movement brought into question the rationality of government policy and priorities, among large numbers of intellectuals of all ages. Second, NDEA fellowship money, combined with widespread draft-dodging among young people unenthused about the war, diverted many of the best minds of a generation away from business and professional schools and into graduate academic training. Third, the protest movement led to the creation of a "counter-culture"-a deliberate effort among young radicals to establish a new way of life (often on the edge of university campuses) that would not perpetuate dominant American cultural practices. The counter-culture quickly absorbed energies that previously had gone into a range of less extreme social movements-including the civil rights efforts of the preceding decade, and the Peace Corps with its flock of disillusioned alumni who had tried to introduce "technological progress" in various parts of the world.

The counter-culture took advantage of new chemical products to reorient previous bases of relationships. Using newly developed contraceptive methods, they experimented with forms of sexual relationship and alternatives to the family as a basic unit of social life. And they began to use psychedelic chemicals and practices from eastern religions to shatter the limits of experienced Reality. At first, it seemed as though the counter-culture was siphoning a portion of that generation out of serious involvement in the creation of cultural products for the larger society. Gradually it has become apparent, however, that it began to have impact not only on those who "dropped out" into it, but also on a much wider circle of young people in university communities and beyond.

Along with all this, an additional movement arose, sponsored in part by those who wished to redirect youthful energy away 
from "protest." The ecology movement began with encouragement from the political establishment as a concern to "clean up America." But it quickly joined forces with the war protest movement to focus attention on the "ecocide" in Southeast Asia, call attention to the role of American corporations in polluting the environment, and challenge the assumption that exponential technological growth was good-or possible over a very long period of time. Most important, the ecology movement began to question the fundamental assumption that humans were the center and controllers of the environment, stressing instead the symbiotic relationships among species and limits to human independent action.

As these styles of thought began to take root among academics, the larger consequences of the Vietnam war began to be visible as well. American dominance began to be seriously challenged, not only militarily but also financially, because of the weakened position of the American dollar in the world economy. The emergence of new coalitions of nations that controlled vital resources and the proliferation of nuclear technology among less technologically developed countries harbingered a more fundamental shift of power based on the capacity to inflict terror on others.

These shifts in the objective position of the nation began to occupy the attention of scholars of all ages, even as the war-generated movements among college-age youth provided new foci for questions. Numerous groups have emerged seeking new meaning for this shattered world (and world view). Included here are groups within the natural and social sciences that make sufficiently distinct assumptions about the basis of reality to be contenders for the status of new paradigm-creators. Two of these, the "futurists" and the "counter-culture physicists," will be examined in some detail. It is much too early to judge, but they offer promise of being more than intellectual fads; and they seem to suggest fundamentally different orientations to the intellectual issues they confront. 


\section{Example 1: The Futurists}

("Secular Judgment")

In the last few years a spate of writings has emerged among social and physical scientists assessing the human prospect. One thinks, for example, of such writers as Robert Heilbroner (1974), Barrington Moore (1972), Buckminster Fuller (1970, 1972, 1973), the group calling themselves the Club of Rome (Meadows et al., 1972), scientists like Dennis Pirages and Paul Erlich (1974), the historian Charles Bright (1975), and others who have extended the assessment of technological society begun ten years ago by Herbert Marcuse (1964). These writers call into question the technological base of current social organization and wam of its imminent collapse. Their prophetic writing can best be described as "secular Judgment." The Futurists, as this "fad" has come to be called, present a modern version of the Fall of Man-a sense that human striving has come to challenge the fundamental order of the universe and is beginning to falter before it.

The Futurists posit an ecological system which effectively limits the range of activities that humans can impose on the world. Many see industrial expansion at its present exponential growth rates ending within the next fifty years, due to limitations on natural resources and energy supplies needed to sustain such activity. And most see the emergence of "nogrowth economies" as requiring fundamental change in the way human beings relate to one another, both within advanced industrial nations that heve depended on industrial expansion for their prosperity, and between nations. Their ecological perspective removes humans from the center of the universe, having dominant control over it through science and technology.

Some of these social prophets shift the Ground of Reality still more radically, relating shifts in bases of dominance and control to the coming necessity of no-growth economies. The historian Charles Bright (1975), for example, forecasts an upswing in political repression within advanced industrial 
nations as no-growth economies emerge: such developments make unworkable the formula by which class struggles over distribution of wealth have been contained in advanced industrial nations over the past eighty years. No longer will exponential growth rates for the economy permit escalation of wages and an expanding tax base for the welfare state, both of which have served to "buy off" worker discontent. More direct repression of dissent is likely as a consequence, he argues.

More importantly, according to Bright, this exponential growth formula cannot be extended to the currently underdeveloped nations, because of resource limitations. Yet they are just now emerging as politically independent, effectively organized areas, with control over key resources, and some now possess nuclear weapons; they are increasingly capable of demanding their share of world wealth.

Thus, argues Bright, we are likely to enter a period of increasing chaos in the next few decades, with nation states unable to deal with the fundamental struggles over resources that emerge, and with the combined ecological limits and "international class struggle" gradually forcing a rethinking of technology and of the kind of science-based relationship patterns that have characterized the modern era. The apocalyptic social forecasters vary in the degree to which they share this sense of the total dissolution of frameworks for orienting social activity. But all of these intellectuals begin with a new sense of where the Ground of Reality lies-one that requires fundamental transformation of human responses.

\section{Example 2: Counter-Culture Physicists ("Secular Mysticism")}

One of the most interesting cultural developments within the last three years has been the emergence of a group of scientists who describe themselves as "counter-culture physicists." In terms of conventional science, they are involved in extending and formalizing the kinds of theories represented by Einstein's theory of relativity. Their focus, however, is upon conscious- 
ness, an area about which conventional science, heretofore, has had little to say (Kauffmann, 1973). It is not unusual for individual physicists to engage in metaphysical speculation, but it is unusual for a network of physicists to focus on questions of this sort as their shared scientific pursuit. Some of them describe the major intellectual task of the next few decades as being that of bringing into one coherent framework insights from science and religion.

As their label for themselves implies, these intellectuals trace the roots of their current inquiry to experiences generated by explorations of the counter-culture. These scholars play the conventional games of academia insofar as normal culture production is concerned. They publish theoretical papers in the standard journals, attend international symposia, seek foundation funds, and establish their credentials as technically competent "producers." But the questions they ask, while discussible within the language of ordinary science, do not grow primarily out of that tradition. They stem from experiences that a few years ago would simply have served to label the participants as mentally deranged (cf. Finkelstein, 1972; Taylor, 1974).

As I see it, the task these younger intellectuals have set for themselves is very much akin to tasks undertaken by many of the best cultural producers in the field of religion. They seem to have begun with their own experience of nonordinary reality. This has included "energy flows" experienced directly between people; unusual experiences of time and space; experiences or observation of precognition, telepathy, clairvoyance, and/or psychokinesis; and shatteringly new senses of how organic and inorganic life are related through time and space. These experiences amount not to a shift of emphasis, but to a virtual dissolution of the ways that time, space, energy, light, matter, organic and inorganic life are assumed to interrelate. Because there was a network of people having similar experiences of this kind, both with and without the aid of drugs, the experiences were accepted as real and as requiring a reformulation of physical principles used to understand experience.

This, of course, is not the first time that physical scientists have explored these areas. Heisenberg's explorations of yoga 
(1971), Einstein's mystic interests (1972), Madame Curie's efforts to communicate with her deceased husband (1974), and the long line of distinguished scientists who have headed British organizations for the study of psychic phenomena attest to an on-going mystical streak within the scientific community. What is different this time is the emergence of a network of scientists taking these kinds of questions not as their focus for scientific observation, but as the orienting perspective for formulating theoretical issues of more general application. They have a journal (Foundations of Physics) and contribute widely to other publications as well, with questions chosen in terms of their relevance to this quest, whether or not other readers recognize the thrust.

For the past few years, theoretical physicists (of both "straight" and "counter-culture" perspectives) have been trying to create a formal statement of theories of gravity, of which Einstein's general relativity theory would be the best known, but not the only version (cf. Will, 1974). The most influential of the recent formulations are what are called metric theories of gravity. These assume that gravitation can be treated as synonymous with the curvature of time and space. This means that all physical systems behave as though the events were taking place in non-Euclidean space-time.

The counter-culture physicists have taken this work a step further. They suggest that negative mass contributes to the geometric shape of space by screening gravitational waves, so that a variety of gravitational fields results (cf. Sciama, 1974; Sarfatti, 1974b). If this is so, each field may be responsible for a particular scale of organization of matter, including biogravitons that organize living systems. With the coexistence of various kinds of gravitational fields, many current understandings of causality principles shift. Time, for example, flows in two directions; space continues to vary by its relation to gravity fields, as Einstein noted, but there are many more possibilities for interconnection in space than seemed true before, including connections between various layers of reality. Thus, causality may flow from the mind and consciousness as well as in the 
other direction. And various combinations of gravitational fields should allow interactions that seem to contradict our present understanding of physical principles. Such "altered states of consciousness" as telepathy, precognition, and even psychokinesis and astral projection become describable in terms of the principles of physics (Walker, 1970; Scarfatti, 1974a).

If this effort to extend general relativity theory in directions that can deal with consciousness is successful, it will reorient many of the questions asked in various intellectual fields-in psychology, physics, philosophy, and religion at the very least. Thus, it potentially dissolves not only the conceptual framework that constricted thought in the past, but also the organizational boundaries that limit who will exchange ideas.

\section{MARKETING REVOLUTION}

In these two examples, we see how secularly produced encounter can lead to conceptual breakthroughs that are religious in quality and that dissolve the hold of the past on ways of seeing, experiencing, and organizing understandings. Earlier I suggested that the market mode within which most intellectual activity is pursued in America coopts and trivializes the revolutionary quality of new formulations so that their impact is diminished. But there are some circumstances under which this method of promotion may actually increase the impact, rather than destroy it.

Packaging ideas as commodities, to be pushed in the same manner that other commodities are, lessens the impact they can make over time-unless that impact depends in part on scale of exposure or on linking specialists who are isolated by conventional disciplinary boundaries. In such cases, the market mode's capacity for promoting symbols as fad items may facilitate the process of new paradigm formation just as, in the quest after profits, mass media corporations disseminated the ethos of the 1960s youth culture (Peterson, 1973).

Three specific examples of how the marketing mode has helped to facilitate the development of counter-culture physics 
and apocalyptic forecasting come to mind. First, a popular paperback book, Psychic Discoveries Behind the Iron Curtain, written in laymen's language by two journalists (Ostrander and Schroeder, 1970), seems to have alerted scientists from many disciplines to areas of common researchable questions that deal with the interaction of consciousness and physical events. Second, a few of the counter-culture physicists have attempted a similar breakthrough of communication, collaborating with an artist-illustrator to produce a cartoon-like exposition of their ideas, with notes alerting the reader to brief summaries of current arguments in general relativity theory and to an annotated bibliography to allow interested readers to delve more deeply (Toben et al., 1975). Third, the apocalyptic forecasters also have written for a general intellectual audience, eschewing technical language and arguments that would limit the audience for their presentation (cf. Pirages and Erlich, 1974).

It is too early to judge the fate of the two cultural breakthroughs just described. They make it clear, however, that the religious mode of inquiry continues to thrive and even uses the market mode to spread its message.

Sometimes cultural breakthroughs lead to conceptual revolutions for a large number of culture consumers; at other times they result simply in the creation of a deviant cult, which sees things differently from the mainstream of humanity, but which has little impact on the way others understand the world. Which result occurs probably depends on three factors: on the social conditions that prevail after the reformulation has been made and that affect receptivity to the new outlook; on the ability of the perspective to produce new insights beyond those which gave it its origin; and on the ability of the new outlook to gain sponsors among gatekeepers to facilities for the dissemination of cultural products.

This paper started from Kuhn's description of conditions for a scientific revolution and has extended the perspective to describe cultural activity more generally. In doing so, it has focused on how modes of inquiry differ, how they nonetheless 
are found across many fields of cultural work, and how "normal cultural production" uses a market mode that changes the character of what is produced. I have argued that conceptual revolutions are based upon a religious mode of inquiry which becomes activated when disruptions occur in the social experience of culture-producing communities. Once generated, such a revolution must be able to incorporate the artistic and scientific modes as well in order to succeed: it must produce experiences that emotionally validate this sense of reality, while clarifying conceptions of how parts of the world relate to one another. The argument has closed by coming full circle once again to Kuhn, offering a more general statement of his argument about conditions affecting the establishment of new paradigms once they emerge.

Revolutions in cultural understandings do not result simply from particular modes of inquiry, from market conditions for the dissemination of ideas, or from shifts in social circumstance for producers of culture alone. Together, however, these factors make possible the kinds of cultural breakthroughs that have revolutionary impact, in which the world is seen anew.

\section{REFERENCES}

BERGER, P. (1969) Sacred Canopy. New York: Doubleday.

BRIGHT, C. (1975) Unpublished manuscripts. University of Michigan, Department of History.

CURIE, M. S. (1974) Correspondence: choix de lettres 1905-1934. Paris: Editeurs francais reunis.

EINSTEIN, A. (1972) Correspondence, 1903-1955. Paris: Hermann.

FINKELSTEIN, D. (1972) "The space-time code." Physical Rev. 5D, 12 (June 15): 2922.

FULLER, R. B. (1973) Earth, Inc. New York: Doubleday.

$---(1972)$ Utopia or Oblivion: The Prospects for Humanity. New York: Overlook. -- (1970) Operating Manual for Spaceship Earth. New York: Touchstone Clarion. HEILBRONER, R. (1974) An Inquiry into the Human Prospect. New York: Norton. HEIRICH, M. (1974) "The sacred as a market economy." Presented at the annual meeting of the American Sociological Association, Montreal.

HEISENBERG, W. (1971) Physics and Beyond. New York: Harper \& Row. 
KAUFFMANN, W. J. III (1973) Relativity and Cosmology. New York: Harper \& Row.

KUHN, T. (1970) The Structure of Scientific Revolutions. Chicago: Univ. of Chicago Press.

MARCUSE, H. (1964) One Dimensional Man. Boston: Beacon.

MEADOWS, D. H., D. L. MEADOWS, J. RANDERS, and W. W. BEHRENS III (1972) The Limits to Growth: A Report from the Club of Rome's Project on the Predicament of Mankind. New York: Universe.

MOORE, B. (1972) Reflections on the Causes of Human Misery and Certain Proposals to Eliminate Them. Boston: Beacon.

OSTRANDER, S. and L. SCHROEDER (1970) Psychic Discoveries Behind the Iron Curtain. Englewood Cliffs, N.J.: Prentice-Hall.

PETERSON, R. A. (1975) "Communalities in the production of high art and low: why cycles?" Social Theory and the Arts Conference, Fredonia, New York.

--- (1973) "The unnatural history of rock festivals: an instance of media facilitation." J. of Popular Music \& Society 2: 1-27.

PIRAGES, D. C. and P. R. ERLICH (1974) Ark II: Social Response to Environmental Imperatives. New York: Viking.

SARFATTI, J. (1974a) "Implications of meta-physics for psychoenergetic systems," Psychoenergetic Systems, Vol. 1. London: Gordon \& Breach.

$---(1974 b)$ "The eightfold way as a consequence of the general theory of relativity." Collective Phenomena 1.

SCIAMA, D. W. (1974) "Gravitational waves and Mach's principle." Trieste, Italy: International Center for Theoretical Physics, Reprint 1C/73/94.

STAPP, H. P. (1971) "S-Matrix interpretation of quantum theory." Physical Review D3: 1303 .

STEIGMAN, G. (1974) "Antimatter in the universe." Int. Rep. IC/73/110. International Center for Theoretical Physics, Trieste, Italy.

TAYLOR, J. G. (1974) Black Holes: The End of the Universe? New York: Random House.

TILLICH, P. (1969) What is Religion? New York: Harper \& Row.

- - (1959) Theology of Culture. New York: Oxford Univ. Press.

TOBEN, B., J. SARFATTI, and F. WOLF (1975) Space, Time and Beyond. New York: E. P. Dutton.

WALKER, E. H. (1970) "The nature of consciousness." Math. Biosciences 7 : 138-178.

WILL, C. M. (1974) “Gravitational theory." Scientific Amer. (November): 25-33. 